\title{
ЗАРУБЕЖНАЯ АРХЕОЛОГИЯ
}

УДК 902.2(574.3)

А.3. Бейсенов

Научно-исследовательский ичентр истории и археологии «Бегазы-Тасмола», Алматы, Казахстан

\section{НАХОДКИ КОСТЕЙ ЖИВОТНЫХ В КУРГАНАХ С «УСАМИ» ЦЕНТРАЛЬНОГО КАЗАХСТАНА}

Особая категория памятников древности - курганы с «усами» - широко распространена на территории Казахстана, а также в ряде регионов за его пределами. Автор на основании своих исследований в предыдущих публикациях высказал мнение о ритуальном характере этих сооружений, которые строились в ходе прощально-поминальных процессов. В сообщении, подготовленном по материалам Центрального Казахстана, рассматриваются кости животных, которые находятся под ритуальной насыпью, а также под камнями полосы «усов». В большинстве случаев это кости лошади. Полные скелеты встречаются редко. В процессе раскопок обычно находят отдельные кости от скелета (часть туши), череп. Во многих случаях сохраняются лишь фрагменты от костей. По костям животных, найденных в курганах с «усами» Центрального Казахстана, получена серия радиоуглеродных дат в лабораториях Великобритании, России, Канады. Часть дат относится к древним периодам. Наряду с этим в ряде случаев радиоуглеродные анализы показывают принадлежность костей животных и к более поздним периодам: тюркскому, кыпчакскому, а также казахскому времени. В работе с костями из курганов с «усами» нужен тщательный подход, особая система учета и анализа.

Ключевые слова: Центральный Казахстан, курганы с «усами», ритуальная насыпь, кости животных, радиоуглеродный анализ.

DOI: $10.14258 /$ tpai(2020)1(29).-08

\section{Введение}

Во многих регионах Казахстана, а также за его пределами распространены курганы с «усами». Наибольшая концентрация их обнаружена в Центральном Казахстане. К настоящему времени опубликовано значительное число работ, где изложены многие проблемы изучения таких памятников, в том числе о их расположении [Маргулан, 1948; Кадырбаев, 1958, 1966; Оразбаев, 1969; Арсланова, 1975; Ахинжанов, 1977; Бейсенов, 1997; 2017; Толеубаев, Бейсенов, Омаров, 1998; Свиридов, 2004; 2005; Боталов, Таиров, Любчанский, 2006; Базарбаева, Джумабекова, 2017; Бейсенов, Логвин, Базарбаева, Грудочко, Сеитов, 2017; Грудочко, 2018; Бейсенов, Хасенова, Ахияров, Дуйсенбай, 2018]. Настоящее сообщение подготовлено по материалам Центрального Казахстана.

Речь пойдет о костях животных, находимых под ритуальной насыпью в системе кургана с «усами». Понятие «ритуальная насыпь» требует некоторого пояснения. Это небольшое сооружение без человеческого захоронения, на восток от которого направлены каменные гряды. В обычной ситуации насыпь одна, гряд две. Это и есть, собственно, курган с «усами», в предложенной автором классификации это тип 1. Такая система бывает пристроена к погребальному сооружению с его восточной стороны, что весьма характерно прежде всего для Центрального Казахстана. Подобные комплексы объединены в тип 2 (2a, 2б). В этом случае с запада находится тасмолинский курган, который обычно называется «основной курган», а с восточной стороны располагается «курган-спутник», от которого идут каменные гряды-«усы», последний и есть «ритуальная насыпь». Встречаются комплексы типа 3, когда курганы распола- 
гаются уже по линии Ю-С. Детальное рассмотрение всех разновидностей курганов с «усами» не входит в задачу настоящего сообщения. Вопросы типологии памятников были уточнены в недавней публикации автора (подробнее см.: [Бейсенов, 2017]), что избавляет нас от ненужного повтора. Только следует еще раз оговориться, что типы памятников рассматриваются автором исключительно по материалам Центрального Казахстана. При нынешнем увеличении числа материалов по курганам с «усами» по разным регионам это обстоятельство следует особо учитывать.

\section{Материалы и методы исследований}

Целые скелеты лошади под ритуальной насыпью встречаются редко. В частности, в материалах М.К. Кадырбаева есть сведения о нескольких курганах. Курган с «усами» №2, исследованный в могильнике Сарша, имел каменную насыпь диаметром 9 м и высотой 1,7 м. Гряды направлены на восток и имеют длину: северная - 198 м, южная - 183 м. Ширина «усов» - 1 м. Человеческое захоронение под насыпью отсутствует. В центре подкурганной площадки найден плохо сохранившийся скелет лошади «крупной породы», положенной «на левый бок, головой на северо-запад (возможно, на юго-запад. - А.Б.), ногами на восток». Вещей нет. В долине реки Былкылдак, близ Кызылтауского подхоза, исследован курган с «усами» №16. Диаметр 9,8 м, верх насыпи снят для строительных работ. «От кургана в восточном направлении отходят „усы“. Длина северного - 86 м, южного - 78,6 м, средняя их ширина - 1 м. ...В полуметровой прямоугольной яме находился истлевший костяк лошади. У передних ног ее найдено железное кольцо (4,8×4,4 см), вероятно, от узды» [Кадырбаев, 1958, с. 102]. В могильнике Карасай исследован курган с «усами» №2. «Диаметр - 11,7 м, высота - 25 см. Насыпь каменная. Курган своими „усами“ обращен на восток. Длина северного „уса“ - 110 м, ширина - 2 м, диаметр каменных набросок у начала $-6,5$ м, в конце -8 м. Длина южного „уса“ - 100 м, ширина - 2 м, диаметр каменных набросок у начала „уса““ - 7,7 м, в конце - 6 м. Под насыпью, на уровне дневной поверхности, обнаружены полуистлевший череп, шейные позвонки и кости передних ног лошади. Материальных находок нет» [Кадырбаев, 1958, с. 103].

Все три кургана состоят из одной насыпи и «усов», таким образом, это тип 1. Во всех трех отмеченных случаях сосуды и их фрагменты отсутствовали.

М.К. Кадырбаев на могильнике Ботакара исследовал курган с «усами» №48. Две насыпи расположены по линии Ю-С (тип 3), на расстоянии 10 м друг от друга. От них на восток отходят две каменные гряды, обе распаханные. Южный курган имел диаметр с севера на юг 5 м, с запада на восток - 10 м. Высота 0,4 м. «Под его насыпью, в западной половине, лежал истлевший скелет лошади, на правом боку, с вытянутыми передними и задними ногами, головой на север». Неподалеку находился «раздавленный глиняный сосуд». Северный курган имел размеры $5 \times 4$ м при высоте 0,4 м. Под его насыпью, также на уровне погребенной почвы и в том же положении, обнаружен скелет лошади, «головой на северо-восток». Там тоже находился «раздавленный сосуд» [Кадырбаев, 1966, с. 346]. В кургане, как видно из описания, найдены скелеты двух лошадей под двумя насыпями. Человеческое погребение отсутствует.

В кургане Кырыкунгир (тип 1), что на склоне Чингистау, найдены кости от двух передних ног молодой лошади, положенные в сочленении, а также обломки ребер и фрагменты от других неопределимых костей животного [Бейсенов, Умиткалиев, Кулькова, 2016, с. 252, рис. 2.-2]. Здесь, похоже, положили часть туши животного. 
В целом ряде других случаев под ритуальной насыпью находят лишь отдельные кости и их фрагменты. Часто сохранность их бывает очень плохой. В кургане Джанайдар (тип 1), близ Улытау, найдены лишь зубы лошади, близ которых лежали детали конской узды раннесакского времени [Оразбаев, 1969]. В 1978 г. М.К. Кадырбаев на Атасу исследовал четыре кургана с «усами». Все курганы относятся к типу 1. «В курганах с „усами“ могильных ям не оказалось. Под насыпями их, на расчищенной площадке лежали кости ног лошади, а в восточной стороне - раздавленные глиняные сосуды» [Кадырбаев, 1978, с. 7]. Под ритуальной насыпью кургана Жамантас (тип 2а) обнаружена округлая яма диаметром 0,8 м и глубиной 0,45 м, на дне которой находились две плохо сохранившиеся трубчатые кости лошади, возможно, молодой особи. За пределами этой ямы, на расстоянии 0,3 м, но уже на уровне древней дневной поверхности лежали зубы лошади [Бейсенов, Дуйсенбай, Святко, 2017].

В кургане с «усами» Атасу-2 (тип 1) обнаружены две ямы, содержавшие предметы гуннского времени. В одной из них также найдены фрагменты костей крупного животного, среди которых можно было узнать одну тазовую кость. Все кости были в таком плохом состоянии, что две заготовленные для ${ }^{14} \mathrm{C}-$ анализа пробы оказались негодными [Бейсенов, Торгоев, Дуйсенбай, Ахияров, 2018]. Под ритуальной насыпью кургана с «усами» №2 (тип 2a) могильника Тандайлы-2 «на материковом уровне найдены три зуба и фрагменты от челюсти лошади. В северной половине подкурганной площадки зафиксировано темное пятно округлой формы, диаметром около 1,1 м. Мощность - 0,2 м. Находки отсутствуют» [Бейсенов, Дуйсенбай, Ахияров, Святко, 2016, c. 236]. Курган с «усами» Кабантау состоит из двух насыпей, расположенных по линии Ю-С, и двух каменных гряд (тип 3). Обе насыпи не имеют могильной ямы, т.е. это ритуальные сооружения. Под северной насыпью костей животных не оказалось. В южной насыпи на 10 см выше материкового уровня найден полуистлевший фрагмент ребра лошади, севернее их на том же уровне находились два мелких фрагмента от неопределенных костей и 7-8 расколовшихся зубов лошади. Все кости лежали в виде полосы по линии Ю-С, длиной 0,5 м. Кости плохой сохранности, для радиоуглеродного анализа оказались непригодными. На расстоянии 1,4 м к северо-востоку от зубов лошади на уровне материка зафиксировано пятно золы диаметром 0,2 м, мощностью 0,1 м. Мелкие кости мелкого рогатого скота найдены также под концевыми сооружениями обеих гряд [Бейсенов, Хасенова, Ахияров, Дуйсенбай, 2018]. Два образца (образцы 2 и 3) были взяты соответственно из костей, найденных под этими двумя сооружениями (табл.).

Курган с «усами» Копа, исследованный автором, состоял из двух насыпей, расположенных по линии 3-В (тип 2а). Западный курган, имевший диаметр 21 м и высоту 1,2 м и относящийся к тасмолинской культуре, содержал сильно ограбленную дромосную могилу. Среди уцелевших вещей - костяные обоймы от воинского наборного пояса, а также фрагменты железного кинжала. Ритуальная насыпь имела диаметр не более 3 м, высота незначительная. Там не найдено ни костей животных, ни развала сосуда. Этот пример не единичен. Ритуальная насыпь кургана Токантас (тип 2а) диаметром 4,5 м и высотой 0,15 м также не содержала ни костей животных, ни керамики. В кургане с «усами» (тип 1) могильника Караоба, а также в кургане с «усами» №3 (тип 1) могильника Кабакши, кости животных и развалы сосудов отсутствовали, но в обоих случаях были найдены каменные жернова, лежавшие на древней поверхности (см.: [Бейсенов, Шульга, Ломан, 2017, с. 27-28, фото 15, 16]). Еще в одном кургане 
с «усами» могильника Караоба, обозначенном как курган с «усами» 2 (тип 2a), ритуальная насыпь тоже не содержала ни костей животных, ни фрагментов сосуда.

Таким образом, кости животных под ритуальной насыпью встречаются в разных вариациях. Можно отметить следующие основные категории:

1) полные скелеты лошадей, уложенных набок;

2) кости от большой части туши лошади, например череп с шейными позвонками и кости передних ног; полные кости от двух ног или от одной ноги;

3) остатки черепа лошади, чаще отдельные фрагменты, зубы;

4) отдельные кости от скелета.

Во всех четырех случаях кости животного могут находиться в неглубокой яме или на древней поверхности.

Сами факты находки под ритуальной насыпью костей и развалов сосудов также варьируют:

1) кости животного, развалы или фрагменты сосуда;

2) кости животного, но нет сосуда;

3) части сосуда, но нет костей животного.

Как было указано, кости животных могут находиться в яме. Бывает ситуация, когда нет костей, но под насыпью фиксируются одна или несколько ям, обычно небольших размеров. Такая ситуация автором встречена в кургане с «усами» №1 (тип 3) могильника Кабакши. Этот случай тоже не единичен. Отдельно стоит еще указать, что помимо костей и зубов лошади иногда достоверно выделяются и кости мелкого рогатого скота, как это было в кургане Кабантау. Под курганом Кызылжар-2 (тип 1) находилась яма размерами $1,2 \times 0,85$ м, глубиной 0,55 м. На дне найдены шесть зубов лошади и полуистлевший фрагмент трубчатой кости мелкого рогатого скота.

Курган с «усами» №1 могильника Кольбасы имел два «спутника», находящихся традиционно с восточной стороны большой насыпи и расположенных по меридиональной линии (тип 2б). Под северной ритуальной насыпью на уровне древней поверхности расчищены кости ноги лошади, положенной в сочленении. Под южной ритуальной насыпью отдельные небольшие скопления костей животных найдены в шести пунктах. Среди них имеются кости и лошади и мелкого рогатого скота. Фрагменты от сосуда найдены под обеими насыпями. Кроме того, под северной насыпью найдена бронзовая литая бляха (рис.) в виде головы животного, с признаками «лося», «верблюда», «грифона». Предмет относится к сакскому времени (раскопки осени 2019 г., материал готовится к публикации).

В целом факты находок костей животных под ритуальными насыпями курганов с «усами» разнообразны и многовариантны. Более упорядоченно представить картину поможет полная сводка имеющихся данных, что предпринимается автором. Учитывается, что в ряде случаев отсутствуют данные о каких-либо находках под ритуальными насыпями. Не говоря о публикациях, материалы раскопок курганов с «усами», обычно не содержащих интересных находок, иногда не попадают даже и в отчеты.

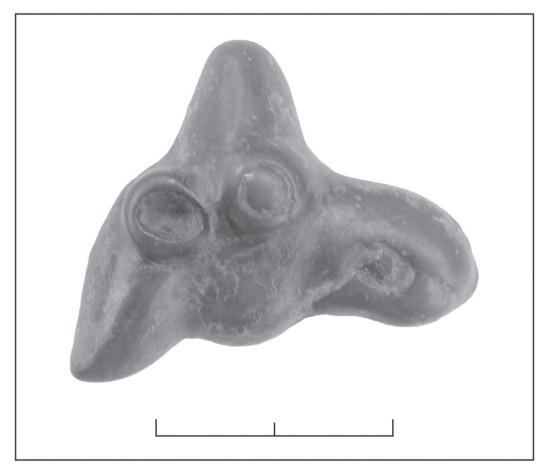

Могильник Кольбасы, курган с «усами» №1. Бронзовая бляха 
Кости животных вкупе с остатками глиняной посуды свидетельствуют о проведении ритуала. Автором еще в ранние периоды работ было сделано предположение о том, что курганы с «усами» строились в ходе прощально-поминальных процессов [Бейсенов, 1997], посвященных умершему соплеменнику. Курганов с «усами» строили очень много. Если учитывать тот факт, что только на территории Центрального Казахстана к современной эпохе сохранились сотни курганов, то приходится обратить внимание на их широко распространенный характер. Эти сооружения, видимо, строились не только для особо избранных. Находки костей животных, а также «раздавленных сосудов» будто бы указывают на основное содержание проведенного ритуала, что уже не раз отмечалось в публикациях автора. Фиксируемое археологами в качестве «ритуальной насыпи» каменное, каменно-земляное, земляное покрытие есть результат того положения, согласно которому центр площадки, где проводился ритуал, а именно участок, где оставляли части туши лошади и части сосудов, необходимо было прикрыть. Неприкосновенной, «сакральной» являлась эта самая площадка, но не сооружение, покрывающее ее.

В какие периоды оставлены кости животных в ритуальных насыпях? Некоторое количество радиоуглеродных дат, полученных при содействии автора, позволяет рассмотреть этот вопрос в самых общих чертах. В ряде случаев кости животных, найденные под ритуальными насыпями, датированы гуннским периодом. Сюда относятся такие памятники, как курган №2 в могильнике Тандайлы-2, курган Жамантас, курган Бесоба-3 (см. табл.) и некоторые другие. Нижняя дата этих трех курганов находится в рамках 1-й трети II - 3-й трети III в. до н.э., а верхняя дата - периода 1-й трети IV - 1-й трети VI в. до н.э. В этой серии самой ранней выглядит дата, полученная по костям животных из ритуальной насыпи кургана №2 из Тандайлы-2, калиброванные значения ее располагаются в рамках периода 130-332 гг. Если судить по наибольшему значению по (0.747, сигма 2), то кости эти оставлены в период 130-266 гг. Это, как видно, самая ранняя «гуннская» дата.

Более ранняя дата получена из кургана с «усами» №1, исследованного в составе могильника Койшокы-5. Комплекс состоит из двух курганов, основного и «спутника», расположенных по линии 3-В (тип 2а), и двух каменных гряд, на протяжении которых имеются упавшие менгиры, а на северной гряде к тому же установлен оленный камень общеевразийского типа. На первом этапе работ были раскопаны оба кургана, а также был вскрыт начальный участок северной гряды. Всего из этого памятника были отобраны пять костных образцов для радиоуглеродного анализа. В том числе четыре даты были получены в лабораториях Великобритании и Канады. Один образец (шифр UBA-39750), полученный из кости животного под ритуальной насыпью, к сожалению, оказался негодным. Образец из кости от человеческого скелета по сигме 2 датирован в пределах 921-810 гг. до н.э. (UBA-39749). Образцы №3-5 были получены из костей мелкого рогатого скота, найденных под камнями вскрытого участка северной гряды«уса». Образец №3 получен из бараньего астрагала (асык), найденного в яме для установки менгира, по сигме 2 датирован (UBA-39751) в пределах 772-431 гг. до н.э. Два остальных образца были получены из мелких костей, найденных под камнями «уса» на уровне материка. Они по сигме 2 дали следующие даты: образец №4 (UBA-39752) 1003-843 гг. до н.э.; образец №5 (Университет Оттавы, Оттава, Канада, шифр JKaz-74) 837-781 гг. до н.э. Планируется полное исследование этого важного памятника, в том числе вскрытие остальных участков обеих гряд, выполнение новых радиоуглеродных анализов (материалы первого этапа исследований находятся в печати). 
AMS ${ }^{14} \mathrm{C}$ даты проанализированных костных образцов из курганов с «усами» Центрального Казахстана

\begin{tabular}{|c|c|c|c|c|}
\hline $\begin{array}{l}\text { Лаборатор- } \\
\text { ный номер }\end{array}$ & Памятник & $14 \mathrm{C} \mathrm{BP}$ & $\begin{array}{c}\text { Калиброванная дата } \\
\text { (Сигма } 1,68.3 \%)\end{array}$ & $\begin{array}{c}\text { Калиброванная дата } \\
\text { (Сигма 2, 95.4\%) }\end{array}$ \\
\hline UBA-28348 & $\begin{array}{l}\text { Тандайлы-2, } \\
\text { курган №2 (тип 2a), } \\
\text { курган-спутник }\end{array}$ & $1795 \pm 36$ & $\begin{array}{c}\text { Cal AD 140-160(0.135) } \\
165-196(0.236) \\
208-256(0.469) \\
299-318(0.160)\end{array}$ & $\begin{array}{c}\text { Cal AD 130-266 (0.747) } \\
270-332(0.253)\end{array}$ \\
\hline UBA-24912 & $\begin{array}{l}\text { Жамантас (тип 2a), } \\
\text { курган-спутник }\end{array}$ & $1654 \pm 30$ & $\begin{array}{c}\text { Cal BC 351-367 (0.188) } \\
379-421(0.812)\end{array}$ & $\begin{array}{c}\text { Cal BC 263-276 (0.016) } \\
329-431(0.919) \\
491-530(0.065)\end{array}$ \\
\hline UBA-28362 & $\begin{array}{l}\text { Бесоба-3 (тип 2a), } \\
\text { курган-спутник }\end{array}$ & $1670 \pm 28$ & $\begin{array}{c}\text { Cal AD 346-372 (0.429) } \\
376-406(0.571)\end{array}$ & $\begin{array}{c}\text { Cal AD } 261-279(0.045) \\
326-425(0.955)\end{array}$ \\
\hline UBA-28358 & $\begin{array}{l}\text { Кабантау (тип 3) } \\
\text { образец №2, концевое } \\
\text { соор. север. «уса» }\end{array}$ & $1564 \pm 29$ & $\begin{array}{c}\text { Cal AD 429-494 (0.765) } \\
509-519(0.097) \\
527-539(0.138)\end{array}$ & Cal AD 420-558 (1.000) \\
\hline UBA-28359 & $\begin{array}{l}\text { Кабантау (тип 3) } \\
\text { образец №3, концевое } \\
\text { соор. южн. «уса» }\end{array}$ & $1555 \pm 29$ & $\begin{array}{c}\text { Cal AD } 430-493(0.750) \\
511-517(0.067) \\
529-544(0.183)\end{array}$ & Cal AD 423-566 (1.000) \\
\hline UBA-24914 & \begin{tabular}{|l|} 
Кызылшилик, \\
курган №2 (тип 2б), \\
образец №3, северный \\
курган-спутник (курган \\
№26), под насыпью \\
\end{tabular} & $99 \pm 28$ & $\begin{array}{c}\text { Cal AD 1695-1726(0.310) } \\
1813-1838(0.239) \\
1842-1853(0.085) \\
1867-1895(0.234) \\
1903-1918(0.132) \\
\end{array}$ & $\begin{array}{c}\text { Cal AD 1683-1734 (0.283) } \\
1809-1929(0.717)\end{array}$ \\
\hline UBA-28355 & $\begin{array}{l}\text { Кызылшилик, } \\
\text { курган №6 (тип 1), } \\
\text { образец №1, } \\
\text { в слое насыпи }\end{array}$ & $140 \pm 24$ & $\begin{array}{c}\text { Cal AD 1680-1696(0.148) } \\
1725-1763(0.281) \\
1801-1814(0.114) \\
1836-1877(0.263) \\
1917-1938(0.195)\end{array}$ & $\begin{array}{c}\text { Cal AD 1670-1709 }(0.167) \\
1717-1779(0.282) \\
1799-1828(0.124) \\
1831-1889(0.255) \\
1910-1943(0.172)\end{array}$ \\
\hline UBA-28356 & \begin{tabular}{|l|} 
Кызылшилик, \\
курган №6 (тип 1), \\
образец №2, под конц. \\
соор. север. «уса» \\
\end{tabular} & $890 \pm 26$ & $\begin{array}{c}\text { Cal AD 1051-1082(0.370) } \\
1128-1133(0.044) \\
1151-1192(0.514) \\
1197-1205(0.072) \\
\end{array}$ & $\begin{array}{c}\text { Cal AD 1043-1103(0.364) } \\
1118-1216(0.636)\end{array}$ \\
\hline UBA-28357 & \begin{tabular}{|l|} 
Кызылшилик, курган №6 \\
(тип 1), образец №3, у края \\
конц. соор. южн. «уса»» \\
\end{tabular} & $1351 \pm 26$ & Cal AD 652-674 (1.000) & $\begin{array}{c}\text { Cal AD 639-694 (0.962) } \\
704-706(0.001) \\
747-762(0.037) \\
\end{array}$ \\
\hline UBA-39739 & $\begin{array}{l}\text { Кабакши, курган №11 } \\
\text { (тип 1), под насыпью }\end{array}$ & $1518 \pm 28$ & $\begin{array}{c}\text { Cal AD 474-485 (0.083) } \\
535-597(0.917)\end{array}$ & $\begin{array}{c}\text { Cal AD 429-494 (0.273) } \\
508-519(0.019) \\
527-610(0.707) \\
\end{array}$ \\
\hline UBA-39740 & $\begin{array}{l}\text { Кабакши, курган №12 } \\
\text { (тип 2б), образец №1, } \\
\text { северный курган- } \\
\text { спутник, под насыпью }\end{array}$ & $1632 \pm 31$ & $\begin{array}{c}\text { Cal AD 384-430(0.762) } \\
493-511(0.152) \\
517-528(0.087)\end{array}$ & $\begin{array}{c}\text { Cal AD 344-474 (0.756) } \\
485-535(0.244)\end{array}$ \\
\hline UBA-39741 & $\begin{array}{l}\text { Кабакши, курган №12 } \\
\text { (тип 2б), образец №2, } \\
\text { под конц. соор. север. } \\
\text { «уса» }\end{array}$ & $1134 \pm 26$ & $\begin{array}{c}\text { Cal AD 887-905 (0.255) } \\
916-967(0.745)\end{array}$ & $\begin{array}{c}\text { Cal AD 778-790 (0.030) } \\
807-819(0.018) \\
824-842(0.028) \\
862-985(0.924) \\
\end{array}$ \\
\hline UBA-39746 & $\begin{array}{l}\text { Кырыкунгир (тип 1), } \\
\text { под насыпью }\end{array}$ & $1615 \pm 32$ & $\begin{array}{c}\text { Cal AD 396-433 (0.499) } \\
462-465(0.023) \\
489-532(0.477) \\
\end{array}$ & Cal AD 384-539 (1.000) \\
\hline UBA-28360 & $\begin{array}{l}\text { Караоба, курган №2 } \\
\text { (тип 2), образец №1, } \\
\text { под конц. соор. север. } \\
\text { «уса» }\end{array}$ & $177 \pm 27$ & $\begin{array}{c}\text { Cal AD 1667-1682(0.184) } \\
1736-1782(0.551) \\
1797-1805(0.092) \\
1935-1950(0.174)\end{array}$ & $\begin{array}{c}\text { Cal AD 1658-1695(0.198) } \\
1726-1813(0.587) \\
1838-1842(0.006) \\
1852-1867(0.018) \\
1918-1950(0.192) \\
\end{array}$ \\
\hline
\end{tabular}




\section{Обсуждение результатов исследований}

Ситуация находок костей животных в курганах с «усами» далеко не так проста, как кажется. Первые результаты радиоуглеродных анализов по памятникам Центрального Казахстана убедительно показывают необходимость разработки особого подхода к этим материалам. Судя по результатам радиоуглеродных анализов, «гуннская» дата, в нашем случае укладывающаяся в рамки периода II-VI вв. до н.э., кажется более стабильной. В имеющейся серии радиоуглеродного анализа наиболее раннюю дату показали образцы из кургана с «усами» №1 из могильника Койшокы-5. Вместе с тем ряд анализов показал, что есть немало случаев, когда кости животных, находимые в ритуальных насыпях, а также под «усами», относятся к более поздним историческим эпохам.

Рассмотрим эти показатели. На могильнике Кызылшилик (подробнее см.: [Бейсенов, Касеналин, 2017]) исследованы два кургана с «усами». В составе кургана с «усами» №2 с восточной стороны западной (погребальной) насыпи расположены два кургана-спутника, обозначенные как курганы №2а и 2б. С этого комплекса, относящегося к типу 26, всего взяты три образца для ${ }^{14} \mathrm{C}$-анализа. Два из них получены из кости человека из могильной ямы под западной насыпью и кости лошади, найденной возле крепиды западной насыпи на уровне материка. Оба этих образца показали даты в рамках тасмолинского времени [Бейсенов, Касеналин, 2017]. Курган-спутник №2a (южная ритуальная насыпь) не дал костей животных. Под насыпью кургана-спутника №2б (северная ритуальная насыпь) найдены кости лошади, откуда был взят третий образец (№3). Этот образец показал дату в рамках казахского периода: конец XVII начало XX в. (табл.).

Точно так же обстоит с датой образца №1 из кургана с «усами» №6 из того же могильника. Данный комплекс состоит из одной насыпи (тип 1), от которой отходят две гряды. С этого комплекса были взяты всего три образца для датирования. Образец №1 взят из кости мелкого рогатого скота, найденной в слое насыпи. Дата образца - казахское время, конец XVII - 1-я половина XX в. (табл.). Образец №2, взятый из слоя концевого сооружения северной гряды, продатирован кыпчакским временем, периодом середины XI - начала XIII в. (табл.). Образец №3 был получен из кости мелкого рогатого скота, найденной под дерновым слоем в непосредственной близости от концевого сооружения южной гряды. Результаты показали, что кость относится к тюркскому периоду: 2-я половина VII - 2-я половина VIII в. (табл.). Таким образом, из четырех костных образцов, происходящих из ритуальных насыпей и каменных гряд двух курганов с «усами» могильника Кызылшилик, ни один не показал период гуннской эпохи. Две даты относятся к казахскому времени, одна - к тюркскому периоду, еще одна - кыпчакскому.

Еще три даты получены недавно (публикуются впервые) по костным образцам из двух курганов с «усами», что в составе могильника Кабакши (табл.). Во всех трех случаях пробы взяты из неопределимых мелких костей животных, найденных под ритуальными насыпями. Курган с «усами» №11 состоит только из одной насыпи и двух гряд (тип 1). Дата костного образца - период 429-610 гг. Курган с «усами» №12 состоит из западной насыпи и двух спутников, примыкающих к ней с востока и расположенных по линии Ю-С (тип 2б). Под западной насыпью могильной ямы и человеческого захоронения не было. Кости животных, части сосудов - отсутствуют. 
Образец №1 был взят из небольшой кости мелкого рогатого скота, найденной под северным спутником на древнем горизонте. Дата - период 344-535 гг. Образец №3 был взят под концевым сооружением северного «уса», кость принадлежит мелкому рогатому скоту. Дата этого образца - период 778-985 гг. Как видно, эта дата более поздняя, чем дата образца №1.

Курган с «усами» №2 могильника Караоба (Каркаралинский район, не путать с Караоба в Прииртышье) состоит из двух насыпей, расположенных по линии 3-В (тип 2a). Под спутником не найдено ни костей животных, ни остатков сосуда. Под камнями концевого сооружения северного «уса» были найдены небольшие фрагменты костей мелкого рогатого скота. Образец №1 (шифр UBA-28360), подготовленный из кости из этого пункта (публикуется впервые), показал дату в рамках казахского периода: 2-я половина XVII - 1-я половина XX в. Как по сигме 1, так и по сигме 2 в качестве наиболее вероятного значения указывают на XVIII в. (табл.).

Мы видим, что рассмотренные даты, полученные из костных образцов из ритуальных насыпей, сильно растянуты по времени.

Кость из ритуальной насыпи кургана №2 могильника Тандайлы-2, наиболее вероятная дата которой находится в пределах 130-266 гг., мы бы отнесли к «раннегуннскому» периоду, а кости из Жамантаса, Бесоба-3 и Кабакши, курган №11 - к гуннскому и позднегуннскому периодам. Есть кости древнетюркского, кыпчакского периодов взятые на концевых сооружениях «усов». Причем кости из таких концевых сооружений «усов» заведомо отделять от костей из ритуальной насыпи не получается, присвоив им некий поздний характер. Ведь кости из двух концевых сооружений комплекса Кабантау дали дату того же гуннского периода!

Есть кости казахского времени. Причем в двух случаях кости взяты уже не из-под «усов», но конкретно под собственно ритуальными насыпями. Если в одном случае кости казахского времени находились в насыпи (Кызылшилик, курган №6), то в другом - под насыпью, на уровне древнего горизонта (Кызылшилик, курган №2).

Впервые кости животного, давшие дату казахского времени, были найдены автором при раскопках тасмолинского жертвенника в урочище Акбеит (подробнее см.: [Бейсенов, 2015]). Тогда автор трактовал факт находки костей казахского времени внутри древнего сооружения, под дерном, в качестве остатков от трапезы казахов в пути. Сейчас видно, что это не так. Судя по всему, оставление кусков мясной пищи или же костей от съеденного мяса в древних сооружениях является малоизвестной нам традицией степных народов, вплоть до казахов нового времени. Учитывается и такой момент. Говоря, например, о костях, датирующихся казахским временем, нельзя это отнести к каким-то случаям закапывания остатков собственного пиршества или ритуальной тризны" в неких уединенных местах. Речь идет о незначительных количествах костей, которые говорят о ритуальном подношении, о символическом

* В старину казахи кости от мясной пищи выбрасывали или сжигали, используя их в качестве топлива. Кости от ритуальных пиршеств, поминок («конакасы», «ас») закапывали в землю или специально сжигали. Выбрасывать их не полагалось. В Центральном Казахстане аульные казахи этого обычая придерживались вплоть до последней трети XX в. На вопрос, почему нельзя выбрасывать кости от поминок, давался обычно двоякий ответ. Во-первых, кости окажутся под ногами людей, животных, их растаскают собаки, звери, и пиршество «не дойдет» до усопшего; во-вторых, ритуал сопровождался чтением Корана, пища освящена, следовательно, остатки этой пищи не следует выбрасывать. 
действии. Для простого закапывания костей от трапезы люди к тому же не ищут кольцевые жертвенники (Акбеит), а также необычные и непонятные по виду сооружения с длинными грядами (курганы с «усами»).

По-видимому, любые находки костей животных в древних памятниках нельзя безоговорочно связывать с данными объектами, культурно-хронологическая принадлежность которых в той или иной степени бывает заранее известна или оговаривается исследователем в ходе процесса. А ведь так делается сплошь, когда встречаются следы тризны, жертвоприношений, какие-либо кострища или просто отдельные кости. Часть таких жертвоприношений, как мы видим, могут быть очень поздними, вплоть до этнографической современности.

Практика показывает, что к находкам костей животных в ритуальных насыпях и на участках каменных гряд рассматриваемых сооружений, как и во множестве других случаев, следует относиться с особым подходом. Хорошо если находят целые кости, хорошей сохранности, в достаточном количестве. Небольшие неопределимые кости, мелкие фрагменты часто выбрасывают, кратко отмечая в отчете лишь факт их находки. Если «неважные» мелкие кости находят в нескольких пунктах под насыпью, их могут смешать.

В кургане с «усами» Кырыкунгир (см. выше) автором, посетившим экспедиционные работы, на раскопках памятника была взята одна кость из части скелета молодой лошади. Это метаподия, из которой в скором времени получена дата из лаборатории Российского педагогического университета им. Герцена (оператор М.А. Кулькова). Этот образец показал дату в рамках тасмолинского периода [Бейсенов, Умиткалиев, Кулькова, 2016]. После этого из кабинета археологии исторического факультета ЕНУ им. Гумилева (Нур-Султан), где хранятся кости из этого памятника, был привезен в Алматы еще один костный образец - для отправки в британскую лабораторию, в Королевский университет Белфаста. Поскольку в этом случае требовался совсем маленький объем материала, был соответственно взят лишь незначительный отпиленный кусок неизвестной кости. Полученная дата относится к гуннскому периоду (табл.). Автор абсолютно уверен в том, что оба образца взяты из костей, найденных под одной и той же насыпью. Но проблема в том, что неизвестно, все ли кости относятся к одному и тому же животному, ведь помимо крупных и относительно целых там находились и другие фрагменты неопределяемых костей!

Как было сказано выше, на кургане с «усами» Кольбасы под двумя ритуальными насыпями был найден целый ряд пунктов с мелкими фрагментами костей животных. Под северным спутником это были, несомненно, кости ноги лошади, положенной в сочленении. Под южным спутником мелкие кости найдены в шести пунктах. В одном случае это были зубы лошади с мелкими фрагментами других костей. В другом - мелкие фрагменты кости мелкого рогатого скота. В остальных четырех случаях определить видовую принадлежность животного вряд ли удастся. В северном спутнике найдена под насыпью тасмолинская бронзовая бляшка. Но покажет ли найденная рядом кость лошади тасмолинскую дату? Если мы получим дату всего лишь из одной кости, будет ли это убедительным для всех семи пунктов? Или же следует делать все семь радиоуглеродных анализов? Для решения сложной задачи с костями животных в ритуальных насыпях курганов с «усами» предпочтительным должен быть именно последний вариант. 


\section{Заключение}

Кости животных являются важной категорией находок при изучении курганов с «усами» Центрального Казахстана и, несмотря на кажущуюся малоинформативность, позволяют ставить и решать соответствующие задачи. Только недавно было начато выполнение радиоуглеродных анализов по таким костям. Планируется продолжение этих работ. Кости животных свидетельствуют о проведении ритуала, и это не является исключительной особенностью для курганов с «усами». Такие факты выявлены, как известно, практически повсеместно для разных исторических эпох. В курганах с «усами» Центрального Казахстана найдены целые туши лошадей и их значительные части, а также отдельные кости как лошади, так и мелкого рогатого скота. Нередко можно обнаружить вообще мелкие и неопределимые фрагменты костей. По-видимому, здесь скрываются две стороны древнего ритуала. В одном случае кости лошади указывают на ритуал жертвоприношения посвященного коня, столь характерный для степных народов вплоть до этнографической современности. Вместе с тем немногочисленные и мелкие фрагменты костей, особенно мелкого рогатого скота, будто бы говорят о ритуале символического подношения, в основе которого лежит то же самое жертвоприношение. Имеющиеся материалы курганов с «усами» Центрального Казахстана, в том числе данные радиоуглеродного анализа, показывают, что этот древний обычай сохранялся там вплоть до казахского времени. Надо полагать, со временем новые материалы дадут возможность более определенно подойти к таким вопросам. В целом для научного анализа костей животных, находимых как под ритуальной насыпью, так и под каменными грядами, должен быть определен особый подход учета и исследования.

\section{Библиографический список}

Арсланова Ф.Х. Курганы с «усами» Восточного Казахстана // Древности Казахстана. Алма-Ата : Наука, 1975. С. 116-129.

Ахинжанов С.М. Курган с «усами» на юго-западных склонах Каратау // Археологические исследования в Отраре. Алма-Ата : Наука, 1977. С. 72-81.

Базарбаева Г.А., Джумабекова Г.С. Новое изваяние эпохи ранних кочевников из Тургая // Самарский научный вестник. 2017. Т. 6, №2 (19). С. 117-121.

Бейсенов А.З. Погребальные памятники и культово-ритуальные сооружения древних номадов Центрального Казахстана (VII-I вв. до н.э.) : Автореф. дис. ... канд. ист. наук. Алматы, 1997. 26 с.

Бейсенов А.З. Околокурганные жертвенники как разновидность памятников тасмолинской культуры // Вестник Томского государственного университета. История. 2015. №4 (36).

Бейсенов А.З. Курганы с «усами» Центрального Казахстана// Археологическое наследие Центрального Казахстана: изучение и сохранение. Алматы : Бегазы-Тасмола, 2017. С. 31-37.

Бейсенов А.З. Тасмолинская культура Центрального Казахстана в исследованиях начала XXI века // Археология и давняя история Украины. 2018. Вып. 2 (27). С. 386-396.

Бейсенов А.З., Дуйсенбай Д.Б., Ахияров И.К., Святко С.В. Радиоуглеродные даты кургана с «усами» из могильника Тандайлы-2 в Центральном Казахстане // Евразия в кайнозое. Стратиграфия, палеоэкология, культуры. 2016. Вып. 5. С. 233-239.

Бейсенов А.З., Дуйсенбай Д.Б., Святко С.В. Курган с «усами» Жамантас // Самарский научный вестник. 2017. Т. 6, №3 (20). С. 227-231.

Бейсенов А.З., Касеналин А.Е. Тасмолинский могильник Кызылшилик // Теория и практика археологических исследований. 2018. №4 (24). С. 85-100.

Бейсенов А.З., Логвин А.В., Базарбаева Г.А., Грудочко И.В., Сеитов А.М. Курганы с каменными грядами Западной Сарыарки // Археологическое наследие Центрального Казахстана: изучение и сохранение. Алматы : Бегазы-Тасмола, 2017. Т. 2. С. 38-49. 
Бейсенов А.З., Торгоев А. И., Дуйсенбай Д.Б., Ахияров И.К. Курган с «усами» Атасу-2 // Поволжская археология. 2018. №3 (25). С. 103-117.

Бейсенов А.З., Хасенова Б.М., Ахияров И.К., Дуйсенбай Д.Б. Курган с «усами» Кабантау // Вестник Дагестанского научного центра. 2018. №71. С. 64-76.

Бейсенов А.З., Умиткалиев У.У., Кулькова М.А. Радиоуглеродная дата кургана с «усами» Кырыкунгир (Восточная Сарыарка) // Евразия в кайнозое. Стратиграфия, палеоэкология, культуры. 2016. Вып. 5. С. 249-255.

Бейсенов А.З., Шульга П.И., Ломан В.Г. Поселения сакской эпохи. Алматы : Бегазы-Тасмола, 2017. 208 c.

Боталов С.Г., Таиров А.Д., Любчанский И.Э. Курганы с «усами» урало-казахстанских степей. Челябинск : Южно-Уральский филиал ИИА УрО РАН, 2006. 232 с.

Грудочко И.В. Курганы с «усами»: типология и проблема культурно-хронологической интерпретации // Маргулановские чтения-2018. Алматы-Актобе : Ин-т археологии им. А.Х. Маргулана, 2018. C. 231-236.

Кадырбаев М.К. О некоторых памятниках ранних кочевников Центрального Казахстана // Известия Ан КазССР. Серия истории, археологии, этнографии. 1958. Вып. 1 (6). С. 95-104.

Кадырбаев М.К. Памятники тасмолинской культуры // Маргулан А.Х., Акишев К.А., Кадырбаев М.К., Оразбаев А.М. Древняя культура Центрального Казахстана. Алма-Ата : Наука, 1966. C. $303-433$.

Кадырбаев М.К. Отчет о работах Центрально-Казахстанской археологической экспедиции за 1978 г. Алматы, 1978 // Архив Института археологии им. А.Х. Маргулана. Оп. 2. Д. 1647. Св. 114.

Оразбаев А.М. Курган с «усами» в могильнике Джанайдар как архитектурный памятник // Культура древних скотоводов и земледельцев Казахстана. Алма-Ата : Наука, 1969. С. 175-191.

Свиридов А.Н. Курганы с «усами» из Акмолинской области (по результатам работы Ишимской археологической экспедиции) // Ахинжановские чтения - 2004. Алматы : Ин-т археологии им. А.Х. Маргулана, 2004. С. 45-51.

Свиридов А.Н. К вопросу о датировке и культурной принадлежности курганов с «усами» // Евразийский ежегодник. Астана : Изд-во ЕНУ им. Л.Н. Гумилева, 2005. С. 152-156.

Толеубаев А.Т., Бейсенов А.З., Омаров Г.К. Курганы с каменными грядами на северных склонах Тарбагатая // Проблемы изучения и сохранения исторического наследия. Алматы : КазНУ, 1998. C. $218-224$.

\section{References}

Arslanova F.H. Kurgany s «usami» Vostochnogo Kazahstana [Mounds with Mountain Ridges of East Kazakhstan]. Drevnosti Kazahstana [Antiquities of Kazakhstan]. Alma-Ata : Nauka, 1975. Pp. 116-129.

Ahinzhanov S.M. Kurgan s «usami» na yugo-zapadnyh sklonah Karatau [Barrow with Ridges on the Southwestern Slopes of Karatau]. Arheologicheskie issledovaniya v Otrare [Archaeological Research in Otrar]. Alma-Ata : Nauka, 1977. Pp. 72-81.

Bazarbaeva G.A., Dzhumabekova G.S. Novoe izvayanie epohi rannih kochevnikov iz Turgaya [A New Statue of the Era of the Early Nomads from Turgai]. Samarskij nauchnyj vestnik [Samara Scientific Bulletin]. 2017. T. 6, №2 (19). Pp. 117-121.

Bejsenov A.Z. Pogrebal'nye pamyatniki i kul'tovo-ritual'nye sooruzheniya drevnih nomadov Central'nogo Kazahstana (VII-I vv. do n.e.) : Avtoref. dis. ... kand. ist. nauk [Funeral Sites and Cult and Ritual Structures of the Ancient Nomads of Central Kazakhstan (the $7^{7^{\text {th }}}-1^{\text {st }}$ centuries BC): Abstract of the Dis. ... Cand. Hist. Sciences]. Almaty, 1997. 26 p.

Bejsenov A.Z. Okolokurgannye zhertvenniki kak raznovidnost' pamyatnikov tasmolinskoj kul'tury [Near-altar Altars as a Kind of Sites of the Tasmola Culture]. Vestnik Tomskogo gosudarstvennogo universiteta [Tomsk State University Bulletin]. Istoriya. 2015. №4 (36).

Bejsenov A.Z. Kurgany s «usami» Central'nogo Kazahstana [Mounds with the Ridges of Central Kazakhstan]. Arheologicheskoe nasledie Central'nogo Kazahstana: izuchenie i sohranenie [Archaeological Heritage of Central Kazakhstan: Study and Preservation]. Almaty : Begazy-Tasmola, 2017. Pp. 31-37.

Bejsenov A.Z. Tasmolinskaya kul'tura Central'nogo Kazahstana v issledovaniyah nachala XXI veka [Tasmolinskaya Culture of Central Kazakhstan in the Studies of the Beginning of the $21^{\text {th }}$ Century]. Arheo- 
logiya i davnyaya istoriya Ukrainy [Archaeology and the Long History of Ukraine]. 2018. Vyp. 2 (27). Pp. 386-396.

Bejsenov A.Z., Dujsenbaj D.B., Ahiyarov I.K., Svyatko S.V. Radiouglerodnye daty kurgana s «usami» iz mogil'nika Tandajly-2 v Central'nom Kazahstane [Radiocarbon Dates of a Barrow with a from the Tandaila-2 Burial Ground in Central Kazakhstan]. Evraziya v kajnozoe. Stratigrafiya, paleoekologiya, kul'tury [Eurasia in the Cenozoic. Stratigraphy, Paleoecology, Cultures]. 2016. Vyp. 5. Pp. 233-239.

Bejsenov A.Z., Dujsenbaj D.B., Svyatko S.V. Kurgan s «usami» Zhamantas [Barrow with the Ridges Zhamantas]. Samarskij nauchnyj vestnik [Samara Scientific Bulletin]. 2017. T. 6, №3 (20). Pp. 227-231.

Bejsenov A.Z., Kasenalin A.E. Tasmolinskij mogil'nik Kyzylshilik [Tasmolinsky Burial Ground Kyzylshilik]. Teoriya i praktika arheologicheskih issledovanij [Theory and Practice of Archaeological Research]. 2018. №4 (24). Pp. 85-100.

Bejsenov A.Z., Logvin A.V., Bazarbaeva G.A., Grudochko I.V., Seitov A.M. Kurgany s kamennymi gryadami Zapadnoj Saryarki [Mounds with Stone Ridges of Western Saryarka]. Arheologicheskoe nasledie Central'nogo Kazahstana: izuchenie i sohranenie [Archaeological Heritage of Central Kazakhstan: Study and Preservation]. Almaty : Begazy-Tasmola, 2017. T. 2. Pp. 38-49.

Bejsenov A.Z., Torgoev A.I., Dujsenbaj D.B., Ahiyarov I.K. Kurgan s «usami» Atasu-2 [Barrow with “Atasu-2" with the Ridges]. Povolzhskaya arheologiya [Volga Archaeology]. 2018. №3 (25). Pp. 103-117.

Bejsenov A.Z., Hasenova B.M., Ahiyarov I.K., Dujsenbaj D.B. Kurgan s «usami» Kabantau [Barrow with the Stone Ridges of Kabantau]. Vestnik Dagestanskogo nauchnogo centra [Bulletin of the Dagestan Scientific Center]. 2018. №71. Pp. 64-76.

Bejsenov A.Z., Umitkaliev U.U., Kul'kova M.A. Radiouglerodnaya data kurgana s «usami» Kyrykungir (Vostochnaya Saryarka) [The Radiocarbon Date of the Mound with the Stoe Ridges Kurikungir (East Saryarka)]. Evraziya v kajnozoe. Stratigrafiya, paleoekologiya, kul'tury [Eurasia in the Cenozoic. Stratigraphy, Paleoecology, Cultures]. 2016. Vyp. 5. Pp. 249-255.

Bejsenov A.Z., Shul'ga P.I., Loman V.G. Poseleniya sakskoj epohi [Saka-era Settlements]. Almaty : Begazy-Tasmola, 2017. 208 p.

Botalov S.G., Tairov A.D., Lyubchanskij I.E. Kurgany s «usami» uralo-kazahstanskih stepej [Mounds with the Stone Ridges of the Ural-Kazakhstan Steppes]. Chelyabinsk : Yuzhno-Ural'skij filial IIA UrO RAN, 2006. 232 p.

Grudochko I.V. Kurgany s «usami»: tipologiya i problema kul'turno-hronologicheskoj interpretacii [Mounds with the Stone Ridges: Typology and the Problem of Cultural-Chronological Interpretation]. Margulanovskie chteniya-2018 [Margulanov Readings-2018]. Almaty-Aktobe : In-t arheologii im. A.H. Margulana, 2018. Pp. 231-236.

Kadyrbaev M.K. O nekotoryh pamyatnikah rannih kochevnikov Central'nogo Kazahstana [About Some Sites of the Early Nomads of Central Kazakhstan]. Izvestiya An KazSSR. Seriya istorii, arheologii, etnografii [Bulletin of the Kazakh SSR. Series of History, Archaeology, Ethnography]. 1958. Vyp. 1 (6). Pp. 95-104.

Kadyrbaev M.K. Pamyatniki tasmolinskoj kul'tury [Sites of the Tasmola Culture]. Margulan A.H., Akishev K.A., Kadyrbaev M.K., Orazbaev A.M. Drevnyaya kul'tura Central'nogo Kazahstana [Ancient Culture of Central Kazakhstan]. Alma-Ata : Nauka, 1966. Pp. 303-433.

Kadyrbaev M.K. Otchet o rabotah Central'no-Kazahstanskoj arheologicheskoj ekspedicii za 1978 g. Almaty, 1978 [Report on the Work of the Central Kazakhstan Archaeological Expedition for 1978]. Arhiv Instituta arheologii im. A.H. Margulana [The Archive of the Margulan Institute of Archaeology]. Op. 2. D. 1647. Sv. 114.

Orazbaev A.M. Kurgan s «usami» v mogil'nike Dzhanajdar kak arhitekturnyj pamyatnik [Barrow with Stone Ridge in the Dzhanaydar Burial Ground as an Architectural Site ]. Kul'tura drevnih skotovodov i zemledel'cev Kazahstana [Culture of Ancient Cattle Breeders and Farmers of Kazakhstan]. Alma-Ata : Nauka, 1969. Pp. 175-191.

Sviridov A.N. Kurgany s «usami» iz Akmolinskoj oblasti (po rezul'tatam raboty Ishimskoj arheologicheskoj ekspedicii) [Mounds with the Stone Ridge from the Akmola Region (Based on the Results of the Ishim Archaeological Expedition)]. Ahinzhanovskie chteniya - 2004 [Akhinzhanov Readings - 2004]. Almaty : In-t arheologii im. A.H. Margulana, 2004. Pp. 45-51. 
Sviridov A.N. K voprosu o datirovke i kul'turnoj prinadlezhnosti kurganov s «usami» [On the Dating and Cultural Affiliation of Barrows with the Stone Ridges]. Evrazijskij ezhegodnik [Eurasian Yearbook]. Astana : Izd-vo ENU im. L.N. Gumileva, 2005. Pp. 152-156.

Toleubaev A.T., Bejsenov A.Z., Omarov G.K. Kurgany s kamennymi gryadami na severnyh sklonah Tarbagataya [Mounds with Stone Ridges on the Northern Slopes of Tarbagatai]. Problemy izucheniya i sohraneniya istoricheskogo naslediya [Problems of the Study and Preservation of Historical Heritage]. Almaty : KazNU, 1998. Pp. 218-224.

\section{A.Z. Beisenov}

\section{Begazy-Tasmola Research Center of History and Archaeology, Almaty, Kazakhstan}

\section{FINDS OF ANIMAL BONES IN THE BARROWS WITH "RIDGES" OF CENTRAL KAZAKHSTAN}

Barrows with "ridges" are widespread in Kazakhstan, as well as in some regions outside it. Based on his research in previous publications, the author expressed an opinion on the ritual nature of these structures, which were built in the course of the farewell and memorial processes.

The report, prepared according to the materials of Central Kazakhstan, considers the bones of animals that are under the mounds, as well as under the stones of the strip of "the ridges".

In most cases, these bones belong to the skeleton of a horse. Full skeletons are rare. During the excavation, individual bones from the skeleton, the skull, are usually found. In many cases, only fragments from the bones are preserved, and very often they are poorly preserved.

On the bones of animals found in mounds with "the ridges" of Central Kazakhstan, the author obtained a series of radiocarbon dates in laboratories in the UK, Russia and Canada.

One part of the dates relates to ancient periods. Along with this, in some cases, ${ }^{14} \mathrm{C}$ analysis shows that the bones of animals belong to later periods: ancient Turkic, Kypchak, and also Kazakh time. In working with bones from barrows with "the ridges", a thorough approach, a special accounting and analysis system are required. analyzes.

Key words: Central Kazakhstan, barrows with "the ridges", ritual mound, animal bones, radiocarbon 